Research Article

\title{
The Air Lubrication Behavior of a Kingsbury Thrust Bearing Demonstration
}

\author{
Wanjun $X u \mathbb{D}^{1,2}$ and Jiangang Yang $\mathbb{D}^{2}$ \\ ${ }^{1}$ School of Energy and Power Engineering, Nanjing Institute of Technology, Nanjing 211167, China \\ ${ }^{2}$ School of Energy and Environment, Southeast University, Nanjing 210096, China \\ Correspondence should be addressed to Jiangang Yang; jgyang@seu.edu.cn
}

Received 22 October 2020; Revised 4 January 2021; Accepted 11 February 2021; Published 27 February 2021

Academic Editor: Keiichi Okai

Copyright (c) 2021 Wanjun $\mathrm{Xu}$ and Jiangang Yang. This is an open access article distributed under the Creative Commons Attribution License, which permits unrestricted use, distribution, and reproduction in any medium, provided the original work is properly cited.

\begin{abstract}
In order to understand the air lubrication behavior of Kingsbury thrust bearing demonstration, an experimental and theoretical investigation on a simulated Kingsbury thrust bearing was presented. The motions of the thrust disk and tilting pads were measured by eddy current sensors for three mass load cases. A simplified theoretical model governing the motion of the thrust disk was established. The bearing successfully passed the examination of lamp extinction and maintained the maximum rotation time of $16 \mathrm{~s}$. The effective hydrodynamic film with a thickness of about $5 \mu \mathrm{m}$ was concentrated on the middle region of the working surface under a flatness of $0.010 \mathrm{~mm}$. The adverse effect of the three surface bumps was minimized by the swing motion of tilting pads. Moreover, about $1 / 3$ air film thickness was shown to be wasted due to the surface irregularity. However, the requirements of surface quality and misalignment were appropriately relaxed through the design of the centrally pivoted tilting pads. This design is conducive to thin-film lubrication and is a potential application for microturbines.
\end{abstract}

\section{Introduction}

The Kingsbury thrust bearing demonstration represents a class of tilting pad gas thrust bearings. It was used by the Kingsbury Company's salesmen to demonstrate the existence of a complete air film. The bearing was simply designed by a thrust disk with three tilting pads, enabling it to operate in a well air-lubricated condition when set in motion by hand. The thrust disk can spin continuously from several seconds to minutes without contact.

The design and manufacture of the bearing are oldfashion without state-of-the-art manufacturing technology. Particularly, emery paper can even be used to grind its working surface. However, this bearing can steadily operate under unfavorable factors such as large surface irregularity and low rotational speed. The adaptive ability to maintain effective lubrication is impressive and worth tapping for modern industrial applications. Gas bearings in microturbines, for example, may learn the bearing design.
To date, there is little research on this bearing from an experimental or theoretical perspective. The internal lubrication condition and necessary mechanism remain unclear. This paper is aimed at (1) systematically studying this bearing and presenting its dynamic characteristics in detail, (2) providing an effective measurement method for air film thickness and the swing motions of tilting pads, and (3) discussing the controversial design of centrally pivoted tilting pads.

Since Hirn [1] proposed the idea of using gas as lubrication in 1854, the technology of gas lubrication has been developed over 160 years. Compared with oil bearings, gas bearings are particularly suitable for high-speed and lightload spindles in precision machinery $[2,3]$. Their main advantages include less friction, high accuracy, and a long lifetime. The applications of gas bearings [4-9] have been extended from traditional gyroscopes and accelerometers to spacecraft simulators, industrial measurement, medical equipment, and microturbines. In the early stage of gas 


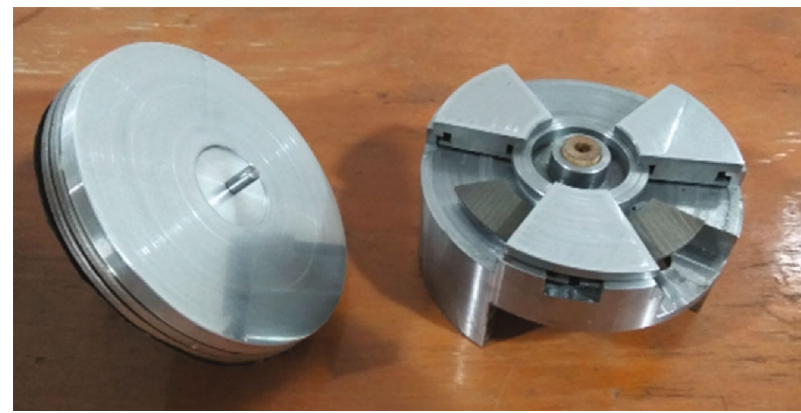

(a) Photo of the bearing apparatus

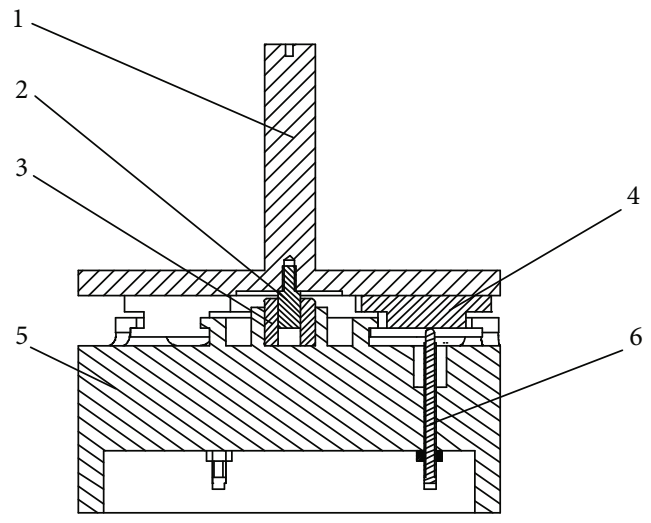

1. Thrust disk

2. Bottom shaft

3. Insulated journal bearing

4. Tilting pads

5. Base

6. Supporting bolts

(b) Sectional view

Figure 1: Simulated Kingsbury thrust bearing.
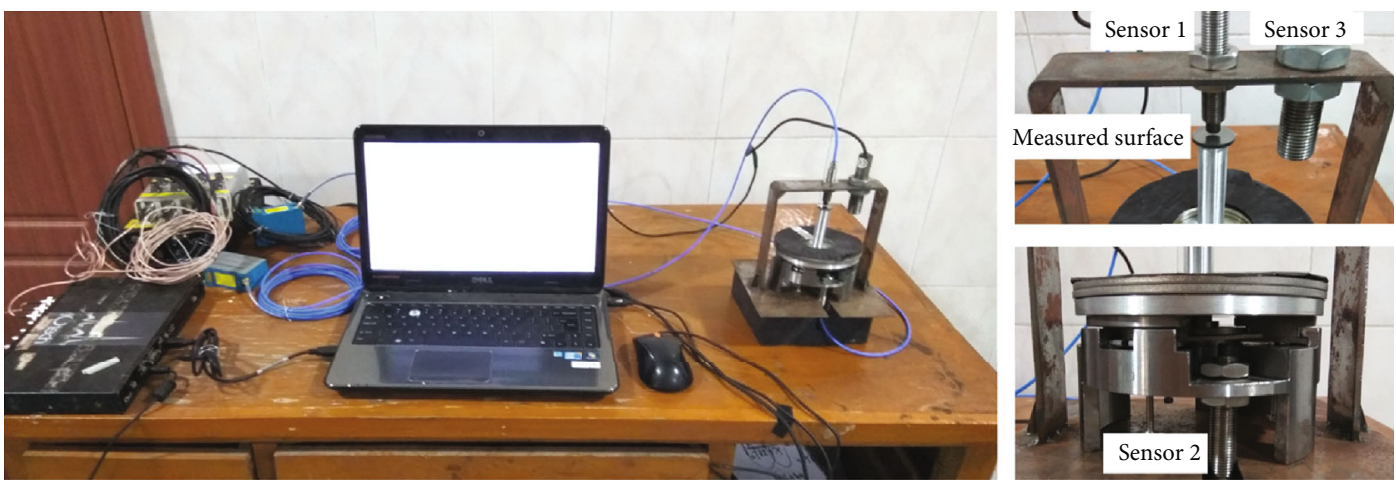

(a) Test rig and sensors

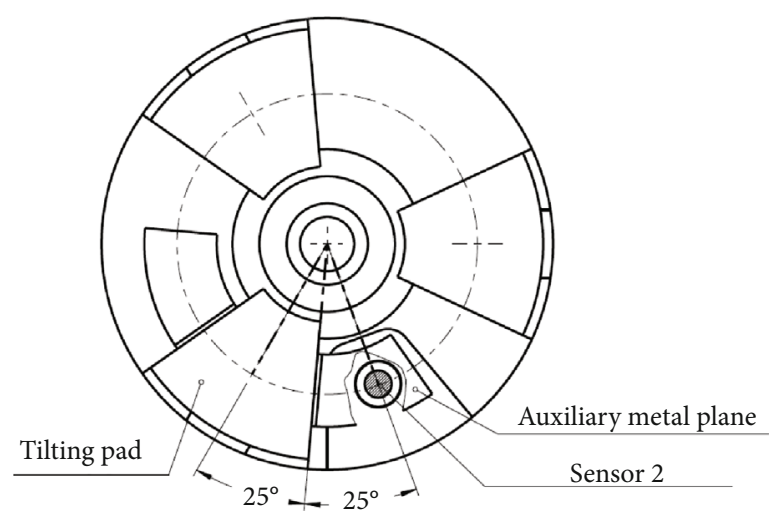

(b) Sensor 2 placement

Figure 2: Test system.

lubrication development, research focused on the measurements of a micron-scale gas film. The method to precisely pick up a micron-scale air film thickness was concerned. In a pioneering work of Kingsbury [10], a small screw of the fine thread was utilized as a sensor to measure the distance between the piston and the cylinder in the test device. The possibility of gas lubrication was verified by this experiment for the first time. With the development of 


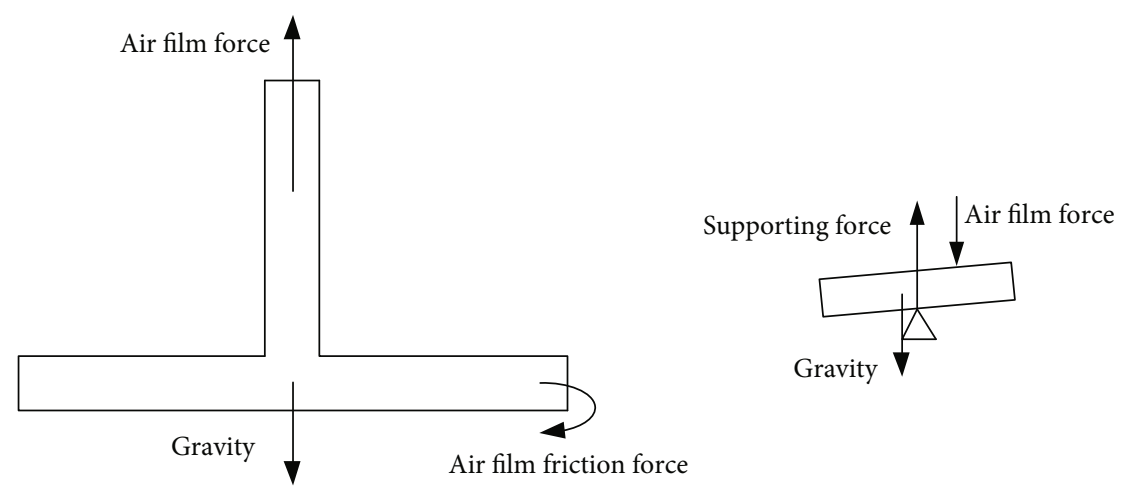

FIgURE 3: Force analyses of the thrust disk and tilting pad.

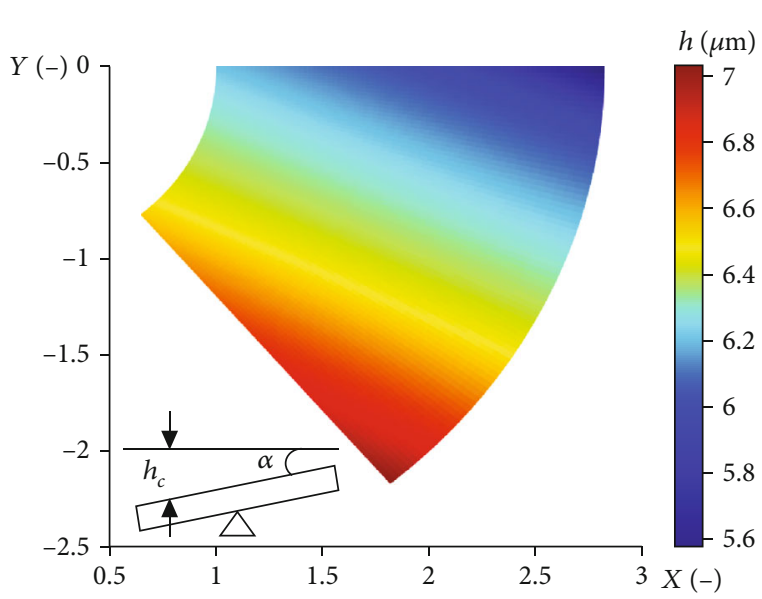

(a) Air film thickness

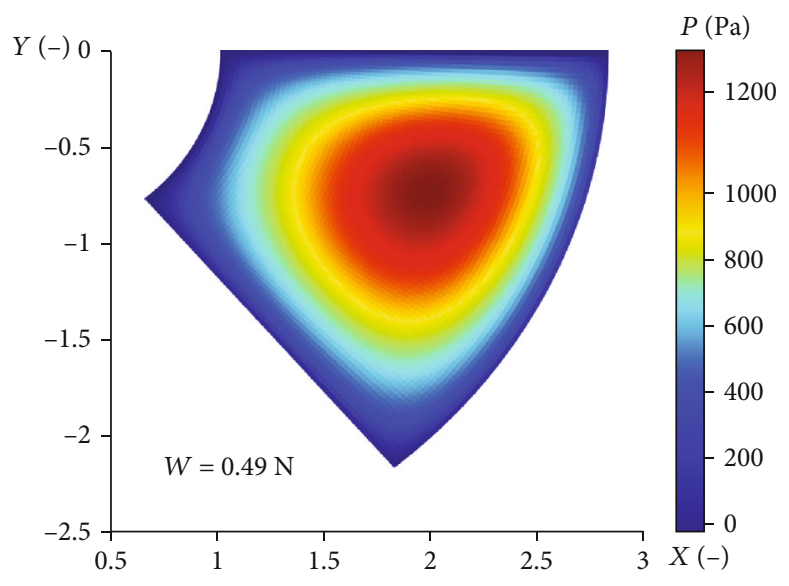

(b) Air film pressure

FIgURE 4: Numerical results.

testing technology, eddy current sensors were largely applied. The measurement of dynamic variation of air films was realized. Many researches [11-14] have shown that the film thickness from $3 \mu \mathrm{m}$ to $50 \mu \mathrm{m}$ was a general working clearance for most gas lubricated devices. What is more, a large film thickness is required for dynamic loads to reduce the possibility of contact.

Benefited from the advanced processing technology, the surface flatness of modern bearings can be minimized to less than $1 \mu \mathrm{m}[15,16]$. The effect of flatness on the air film is less. Research focused on the improvement of the load-carrying capacity [17-20]. In the Kingsbury thrust bearing demonstration, however, the quality of the surface made by the grinding process of emery paper is relatively low. It implies an imperfect lubrication condition. The possibility of surface contact is increased, especially when the bearing operates at a low rotational speed; in addition, the misalignment of shaft-bearing is required more strictly. In this study, a simulated Kingsbury thrust bearing was tested for three mass load cases at a speed of less than $350 \mathrm{r} / \mathrm{min}$. The internal lubrication condition and dynamic characteristics of the bearing were studied. The axial motion of the thrust disk and the swing motion of the tilting pads were measured. A simplified theoretical model was established to explain the operating behavior of the bearing.

\section{Apparatus}

The Kingsbury thrust bearing was simulated to explore its operating behavior, as illustrated in Figure 1. The bearing elements consist of a thrust disk, three tilting pads, three supporting bolts, and a base. The thrust disk was flexibly positioned on the three tilting pads, and the bottom center shaft was inserted into the insulated journal bearing of the base. The tilting pads were placed in the slots of the base and supported by the point pivots of the bolts. This arrangement allows the pads to more freely. Besides, the surfaces of the thrust disk and tilting pads can contact closely by adjusting the bolts to a suitable elevation. The thrust disk is composed of aluminum with a diameter of $100 \mathrm{~mm}$. Its mass is $0.15 \mathrm{~kg}$ and can be increased by the addition of extra metal rings on the surface. The tilting pads are the 50-degree fan-shaped stainless steel with the inner and outer diameter of $35 \mathrm{~mm}$ and $95 \mathrm{~mm}$, respectively. The working surfaces of the two parts were ground smooth with 2000-grit emery paper.

An eddy current sensor, Sensor 1, with a probe diameter of $5 \mathrm{~mm}$ was placed on top of the thrust disk to measure the axial displacement, as shown in Figure 2. The diameter of the measured surface was enlarged to $20 \mathrm{~mm}$ 


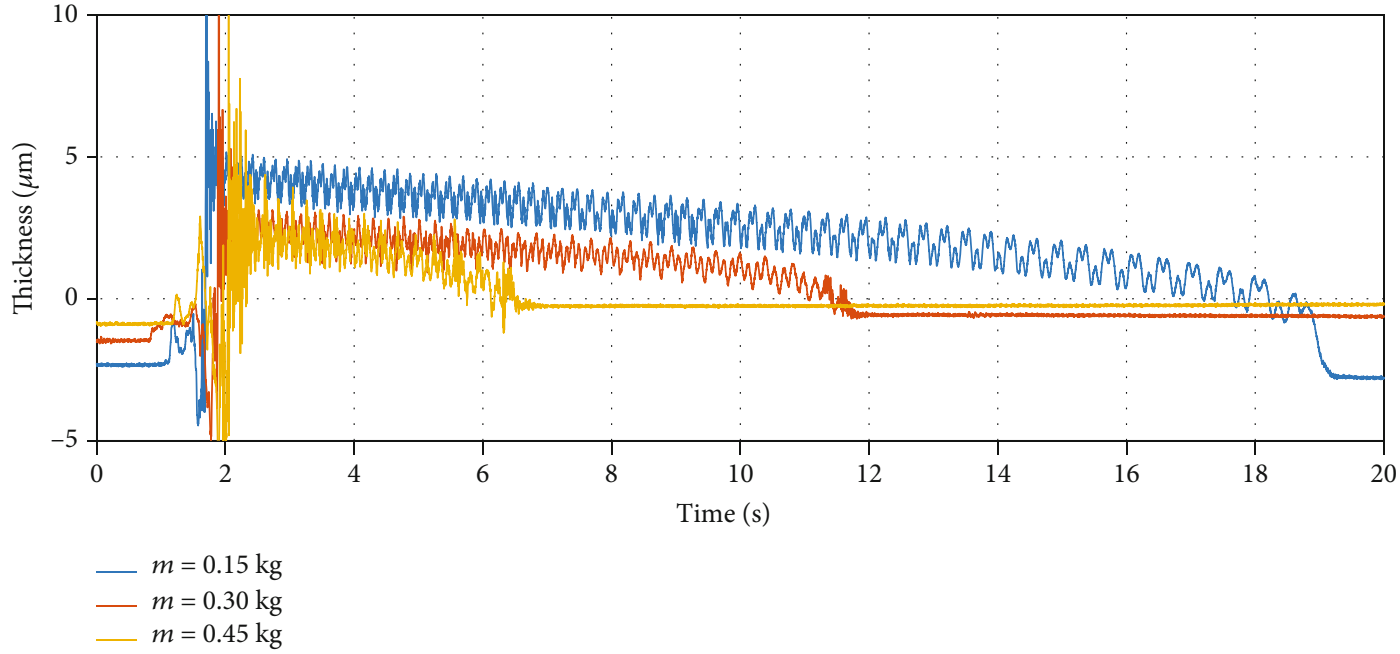

(a) Axial displacement of the thrust disk

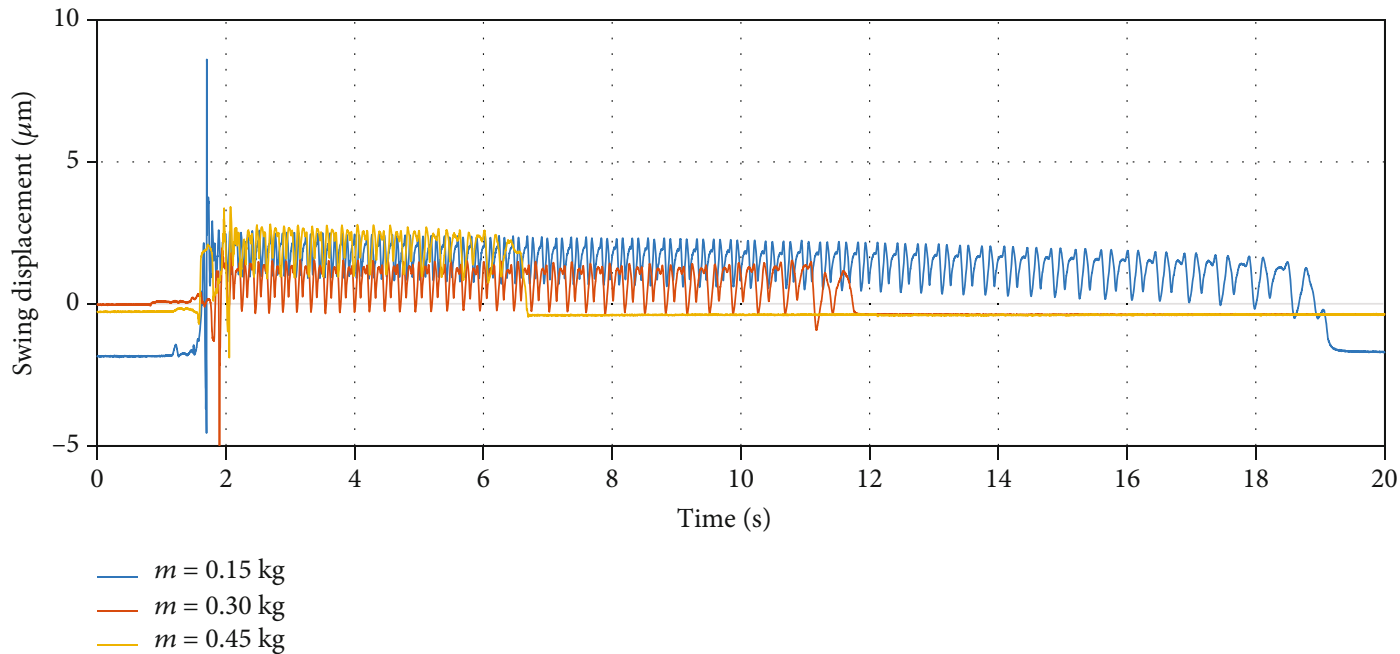

(b) Swing displacement of the tilting pad

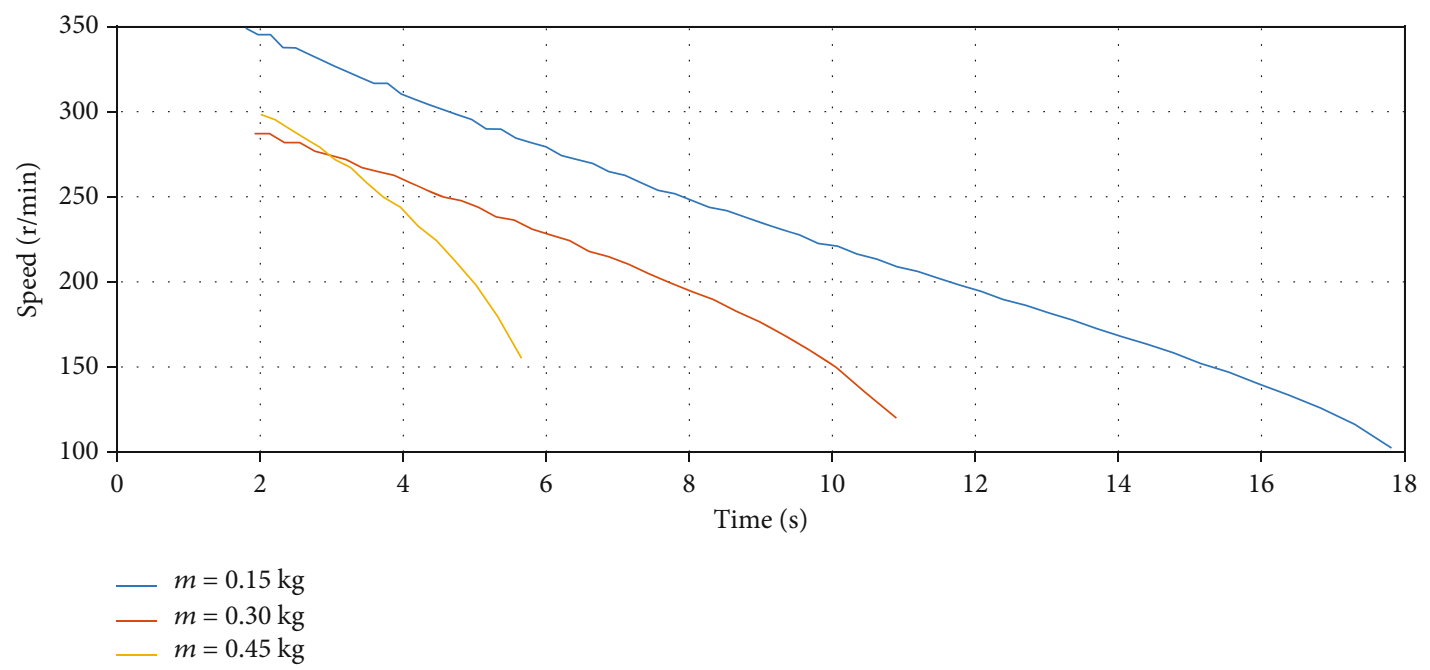

(c) Rotational speed of the thrust disk

FIGURE 5: Experimental results. 
TABLE 1: Initial conditions and parameters.

\begin{tabular}{lcccccc}
\hline Cases & $\begin{array}{c}m \\
(\mathrm{~kg})\end{array}$ & $\begin{array}{c}G_{1} \\
(\mathrm{~N})\end{array}$ & $\begin{array}{c}N_{0} \\
(\mathrm{r} / \mathrm{min})\end{array}$ & $\begin{array}{c}h_{c 0} \\
(\mu \mathrm{m})\end{array}$ & $\begin{array}{c}T \\
(\mathrm{~s})\end{array}$ & $\begin{array}{c}\text { Common } \\
\text { parameters }\end{array}$ \\
\hline $\begin{array}{l}\text { Case } \\
1\end{array}$ & 0.15 & 1.47 & 350 & 6.3 & 16 & $\begin{array}{c}\mu=1.86 \times 10^{-5} \\
\mathrm{~Pa} \cdot \mathrm{s}\end{array}$ \\
$\begin{array}{l}\text { Case } \\
2\end{array}$ & 0.30 & 2.94 & 280 & 4.8 & 9.5 & $c_{1}=0 \mathrm{~N} \cdot \mathrm{s} / \mathrm{m}$ \\
$\begin{array}{l}\text { Case } \\
3\end{array}$ & 0.45 & 4.41 & 300 & 4.1 & 4.5 & $\alpha=0.002^{\circ}$ \\
\hline
\end{tabular}

after being glued on a steel ring. Another eddy current sensor, Sensor 2, was positioned on the base between the tilting pads. Its probe faced the auxiliary steel plane, which was combined with the tilting pad (see Figure 2(b)). This combination allows the swing displacement of the tilting pad to be measured. The rotational speed of the thrust disk was measured by a photoelectric sensor, Sensor 3 . All of the test data was recorded in the software of eZTOMAS 8.0 when the thrust disk was set in motion by hand.

\section{Simplified Model}

The force analyses of the thrust disk and tilting pads are presented in Figure 3. The thrust disk was floated on an air film and subjected mainly to the air film force, air film friction force, and gravity. The angular motion is ignored. Then, the axial motion of the thrust disk is simply governed by

$$
m \ddot{z}+c_{1} \dot{z}+3 W(z)=G
$$

where $m$ is the mass of the thrust disk, $z$ is the axial displacement, $c_{1}$ is the axial damping of air film, $W$ is the air film force, and $G$ is the gravity of the thrust disk.

The tilting pad swings on its pivot and is subjected mainly to the air film force, supporting force, and gravity. Its swing motion is determined by

$$
J \ddot{\alpha}+c_{2} \dot{\alpha}+M_{W}(\alpha)=M_{G},
$$

where $J$ is the rotational inertia of the tilting pad, $\alpha$ is the swing angle, $c_{2}$ is the swing damping of air film, $M_{W}$ is the moment of the air film force, and $M_{G}$ is the gravity moment.

The air film force $W$ can be better calculated by numerical methods due to the finite size of the tilting pads. The compressible dimensionless Reynolds equation (Equation (3)) was solved by a finite difference method (FDM):

$$
\frac{\partial}{\partial R}\left[P R H^{3} \frac{\partial P}{\partial R}\right]+\frac{1}{R} \frac{\partial}{\partial \theta}\left[P H^{3} \frac{\partial P}{\partial \theta}\right]=\Lambda R \frac{\partial(P H)}{\partial \theta} .
$$

The parameters in Equation (3) have been illustrated in Reference [21]. The dimensionless thickness $H$ of air film must be determined. It is characterized by the air film central thickness $h_{c}$ and the swing angle $\alpha$, as expressed in

$$
H=\frac{h_{c}+(\theta-\varphi) R r_{i} \tan \alpha}{h_{c}},
$$

where $\varphi=0.4364$ radians (25 degrees) indicates the halfangle of the tilting pad, $r_{i}=0.017 \mathrm{~m}$ indicates the inner radius of the tilting pad, and $\alpha=0.002^{\circ}$ indicates the assumed swing angle. The discretization and iterative scheme were detailed in Reference [21]. The air film force is calculated as

$$
W=\int_{r_{i}}^{r_{0}} \int_{0}^{50 \circ} p r d r d \theta
$$

The obtained results were explained for the case of $h_{c}=$ $6.3 \mu \mathrm{m}$ and $N=350 \mathrm{r} / \mathrm{min}$. The air film thickness and pressure distribution are presented in Figure 4. The maximum and minimum film thicknesses appear at the sides of the tilting pad along the outermost diameter. The primary hydrodynamic pressure is concentrated on the center of the tilting pad. The boundary pressure of the tilting pad is kept at zero. The air film force is calculated as $W=0.49 \mathrm{~N}$ after the pressure integral performs. The total air film force is three times that of the single air film force and equals the gravity of the thrust disk.

\section{Results and Discussion}

The bearing was measured under the thrust disks with a mass of $0.15 \mathrm{~kg}, 0.30 \mathrm{~kg}$, and $0.45 \mathrm{~kg}$, respectively. The bearing passed the examination of lamp extinction at each mass load case. The behavior of the lamp in a complete testing process was presented as completely extinguished to flicker and finally to normal light. The flicker implies that local contact appeared at the end of the testing. The experiment verified that a complete air film was formed between the thrust disk and the tilting pads.

Figure 5(a) illustrates the axial displacement of the thrust disk, which represents the air film central thickness. The initial displacement was observed to be negative, inconsistent with the actual condition. This is mainly caused by the algorithm or hardware problem of the test system, in which the starting point cannot be calibrated accurately. However, the negative displacement does not affect the validity of the test results because the required data is the displacement difference. The thrust disk was rapidly floating up to about $5 \mu \mathrm{m}$ once it was set in motion by hand; then, it gradually dropped until complete contact. The longest-running time is $16 \mathrm{~s}$ in the light case of the $0.15 \mathrm{~kg}$ thrust disk. The running time depends on the initial speed and surface conditions. Once a smoother surface is offered by extended polishing, an increased spin time will be obtained. In the process of disk dropping, the thrust disk motion was accompanied by a fluctuation at the rotational frequency resulting from the unparalleled measured surface (see Figure 2(a)). Its rotational motion generated a harmonic fluctuation that was combined in the axial displacement curve. This scenario was more evident when there was a larger misalignment between the 


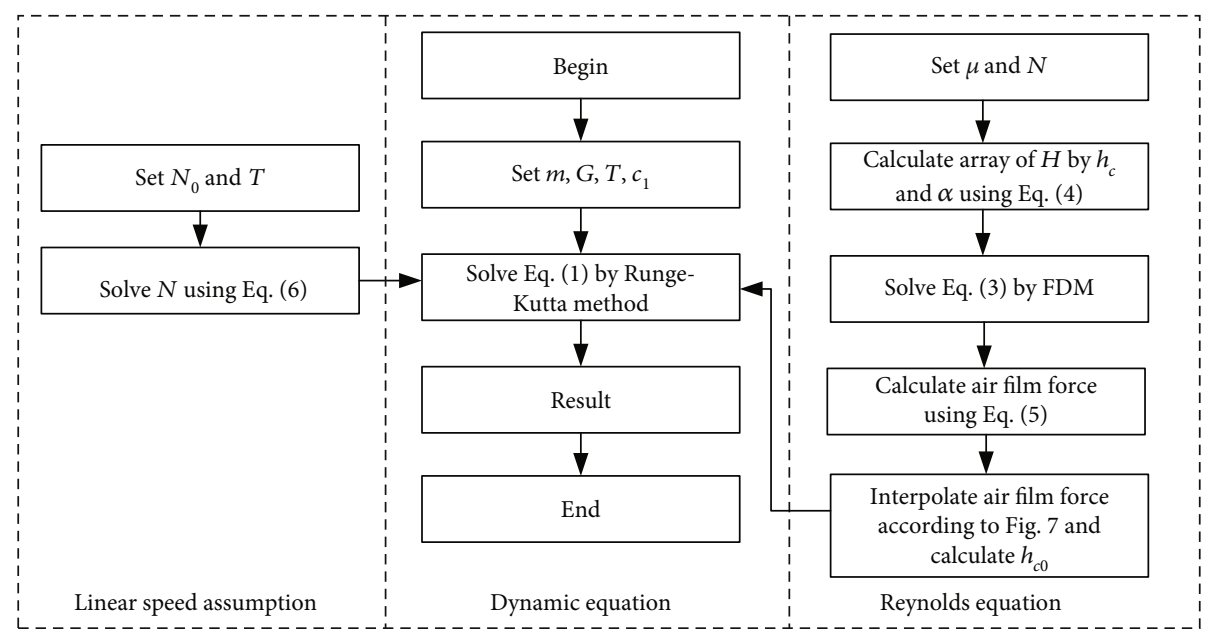

Figure 6: Flow chart of the solution process.
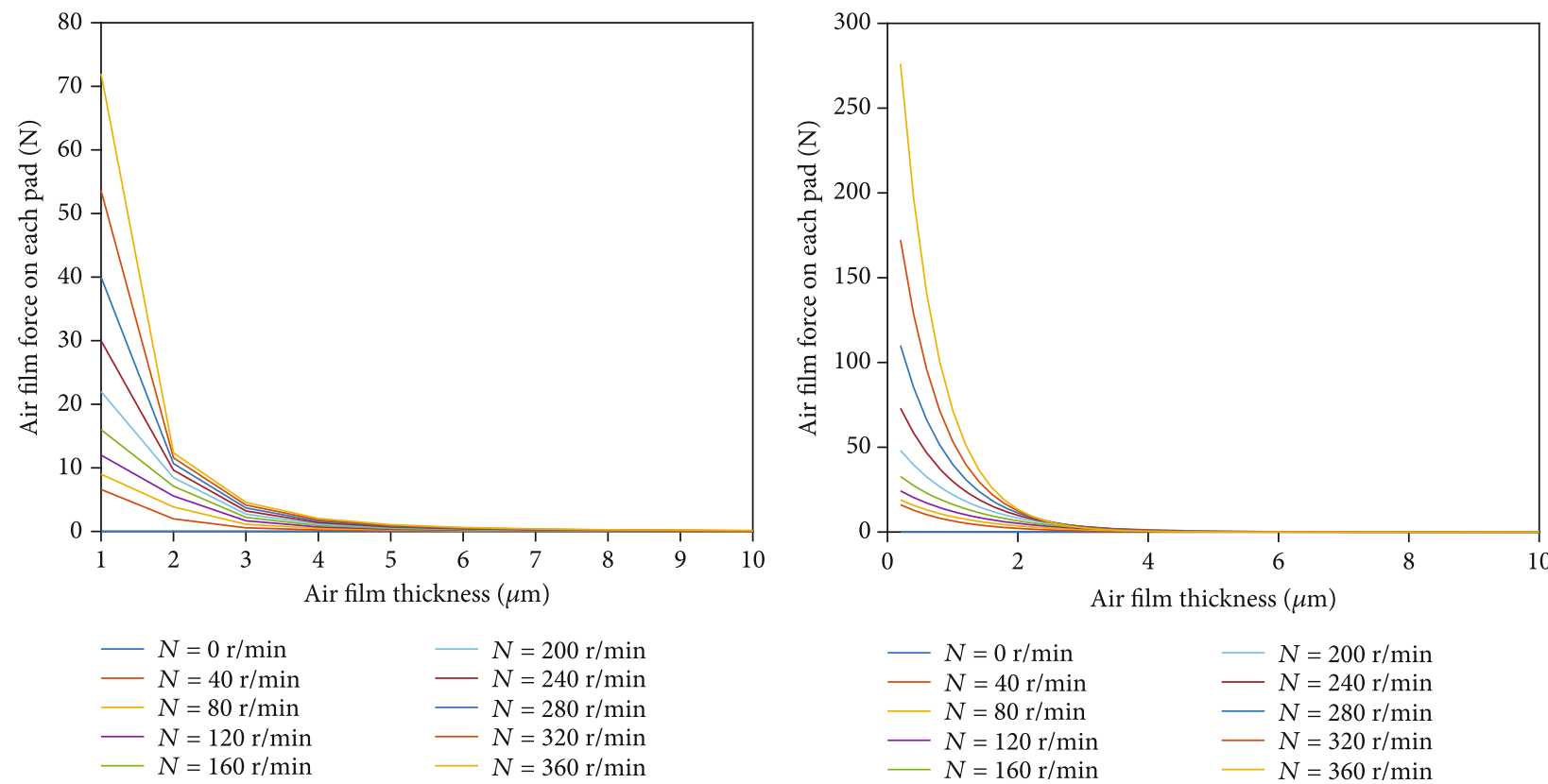

(b) Exponential fitting

(a) Air film force from Reynolds equation

FIGURE 7: Interpolation process.

sensor probe and the thrust disk axis. Those fluctuations are hard to be completely removed based on the current measurement method. They are just considered interference and ignored.

Two assumptions were made to close Equation (1) to theoretically calculate the air film thickness. The rotational speed was set to a linear decrease, in line with the experimental results (see Figure 5(c)), as follows:

$$
N=N_{0}-\frac{N_{0}}{T} t
$$

where $N_{0}$ is the initial rotational speed, $T$ is the total running time, and $t$ is the time. The swing angle of the tilting pads was set to a fixed value (The tilting pad motion will be discussed later.). Based on these assumptions, Equation (1) was solved using the $4^{\text {th }}$ Runge-Kutta method. The corresponding initial conditions and parameters are listed in Table 1. The flow chart of the solution process is provided in Figure 6. The air film force at each time step was updated according to the solution of the Reynolds equation. There is a large time consumption in the solution of the Reynolds equation in practical calculation. To overcome this problem, the air film force from the Reynolds equation was predetermined through the calculation of a series of film thickness and rotational speed, as illustrated in Figure 7(a). The air film force used in Equation (1) at each time step was calculated by the interpolation of two adjacent curves, contributing to 


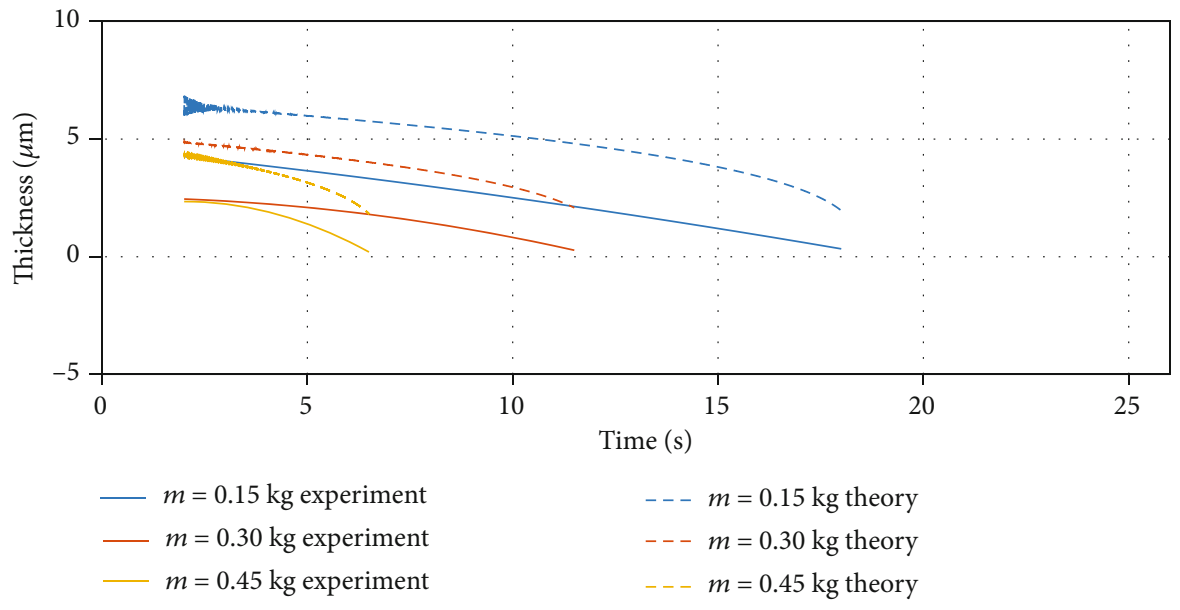

FIgURE 8: Comparison of air film thicknesses obtained by experiment and model.

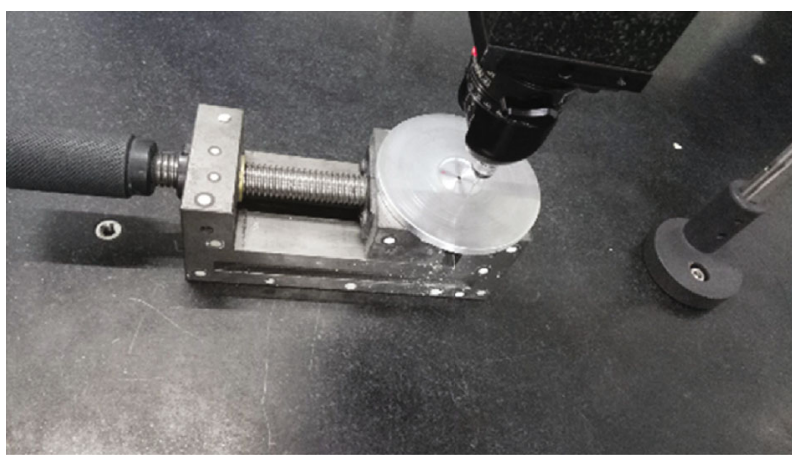

(a) Measurement in CMM

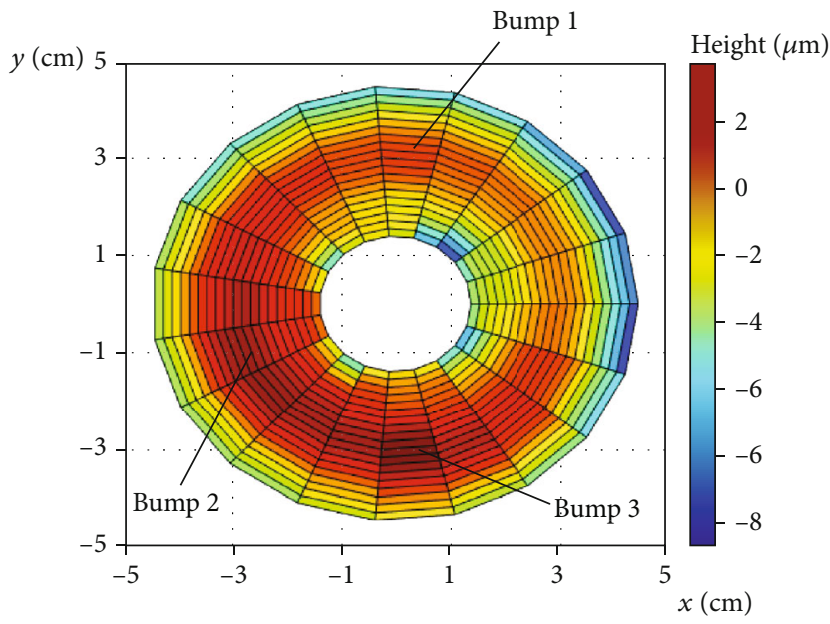

(b) Height contour of the surface

FIgURE 9: Flatness of the working surface.

avoiding large time consumption. Moreover, these curves were fitted through an exponential relation to ensure the smoothness of the solution (Figure 7(b)).

Besides, the initial air film central thickness $h_{c 0}$, one of the initial parameters of Equation (1), needs to be predetermined. The total air film force is always equal to the thrust disk gravity in the operating process. The value of $h_{c 0}$ was calculated using the force equilibrium relation. Additionally, the air film damping $c_{1}$ was ignored owing to the weak effect.

The air film thickness was calculated based on the assumed rotational speed. Essentially, it is a pseudotransient analysis that the whole transient solutions are made up of a series of steady-state solutions. The pseudotransient analysis is a simplified theoretical model that reduces calculation cost and shows the variation of air film thickness. The air film thickness between the experiment (the fluctuation was ignored) and the model was compared in Figure 8 . The same trend for air film thickness is observed; however, the calculated air film thickness is about 2 times higher than that of the measurement. The air film thickness was overpredicted because the theoretical model neglected the adverse effects such as surface irregularity. The flatness of the bottom surface of the thrust disk was measured by a Coordinate Measuring Machining (CMM) to present the details of the actual lubrication (Figure 9(a)). The height contour is presented in Figure 9(b). The circumferential region at the middle radius is higher than the side regions. The maximum height difference is around $10 \mu \mathrm{m}$, implying that the surface flatness is $0.010 \mathrm{~mm}$. In this case, the effective air film must be concentrated on the middle region, which occupies $2 / 3$ of the total area of the surface. Regarding the side regions, the large gap hinders the generation of effective load-carrying capacity. The thrust disk gravity is entirely born by the middle air film. Therefore, the air film thickness has to become about $1 / 3$ of the theoretical air film thickness to achieve higher load-carrying capacity. This causes the air film thickness in the actual lubrication to be smaller than that in the model. Consequently, the dynamic performance is reduced by the surface irregularity. 

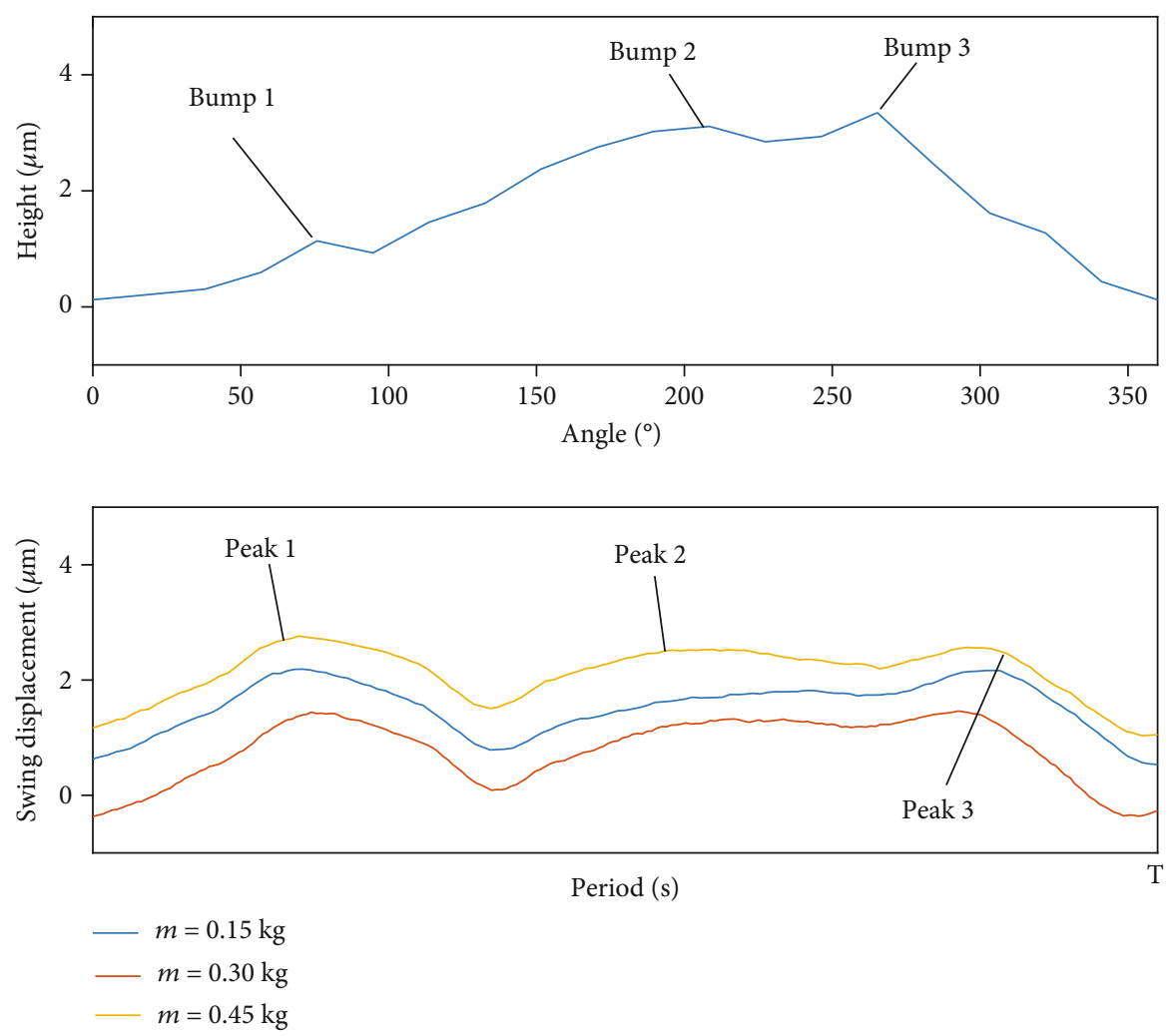

FIGURE 10: Comparison of surface flatness and tilting pad motion.

The swing displacement of the tilting pads is shown in Figure 5(b). The tilting pads were initially horizontal and suddenly swung when the rotation began. The swing motions of the three mass load cases were the same. These fluctuations in the measurements were represented by two or three peaks and repeated in each rotational period. The peak amplitude $h_{p}$ is about $1 \mu \mathrm{m}$, suggesting that the swing angle $\alpha$ is about $0.002^{\circ}$, as calculated by

$$
\alpha=\tan ^{-1} \frac{h_{p}}{r_{s} \psi}
$$

where $r_{s}=0.033 \mathrm{~m}$ indicates the radius positioned Sensor 2 and $\psi=0.8727$ radians (50 degrees) indicates the angle between Sensor 2 and the tilting pad center.

The swing motion of tilting pads may be caused by two reasons: the design of central pivots and the surface irregularities. The tilting pads were designed by pivoting centrally to effectively eliminate the misalignment. However, this design has been criticized in [22] because the pivot should be placed in the center of pressure in theory; otherwise, the bearing becomes unstable. The total air film force always appears at the side of the small gap, resulting in an unbalanced moment. The tilting pads may swing at a frequency.

However, the tilting pads did not strictly pivot centrally during the testing. The top diameter of the supporting bolts is $2 \mathrm{~mm}$, and the width of the slot at the bottom of the tilting pads is $3 \mathrm{~mm}$. The tilting pad can self-adjust to a suitable position, making the air film force point to the pivot to eliminate the unbalanced moment. The experimental results indicated that the swing frequency was related to the rotational frequency. Thus, the surface irregularity is the main reason.

According to the flatness measurement, the surface was subjected to three bumps with a height of $1.1 \mu \mathrm{m}$, $3.1 \mu \mathrm{m}$, and $3.3 \mu \mathrm{m}$, respectively. When the bumps passed through the top surface of the tilting pads, the tilting pads had to be swung to maintain the necessary convergence gap and generate load-carrying capacity. These bumps caused the swing motion of the tilting pads in each rotational period. The surface irregularity and the tilting pad motion were compared, as illustrated in Figure 10. The height curve was plotted at the middle radius of the surface. The three bumps basically corresponded to the three-time swings of the tilting pad in each rotational period. Due to inertia and multidimensional effect, the swing of the tilting pad was smooth and lagged behind the variation of the surface height. Compared with fixed pads, the tilting pads self-adjusted the air film thickness with the changing surface height. Consequently, the possibility of contact was extremely reduced, and the lubrication ability was improved.

\section{Conclusion}

The excellent adaptive ability was presented by the simulated bearing. The adverse effect of the surface bumps was minimized by the swing motion of tilting pads, and a complete air film was formed between the gap. The 
effective air film thickness of about $5 \mu \mathrm{m}$ was concentrated on the middle region of the surface, though the surface flatness reached $0.010 \mathrm{~mm}$. However, the theoretical models indicated that about $1 / 3$ air film thickness was wasted due to the surface irregularity. The design of the centrally pivoted tilting pads is of particular significance, making the bottom surface of the thrust disk completely fit the tilting pads. The requirement of surface processing technology is appropriately relaxed. This design does not make bearing unstable. It contributes to thin-film lubrication and is a potential application for microturbines.

\section{Nomenclature}

$H: \quad$ Dimensionless air film thickness

G: $\quad$ Gravity of thrust disk

$J: \quad$ Rotational inertia of tilting pad

$M_{G}:$ Gravity moment

$M_{W}$ : Moment of air film force

$T: \quad$ Total running time

$N$ : $\quad$ Rotational speed

$N_{0}$ : Initial rotational speed

$W: \quad$ Air film force

$c_{1}, c_{2}:$ Damping

$h_{c}: \quad$ Air film central thickness

$h_{c 0}$ : Initial air film central thickness

$h_{p}$ : Peak amplitude

$m$ : $\quad$ Mass of thrust disk

$r_{i}$ : Inner radius of the tilting pad

$r_{s}: \quad$ Radius positioned Sensor 2

$t$ : Time

$z$ : Axial displacement

$\alpha$ : $\quad$ Swing angle

$\varphi$ : Half-angle of tilting pad

$\psi$ : $\quad$ Angle between Sensor 2 and tilting pad center.

\section{Data Availability}

The data used to support the findings of this study are included within the article.

\section{Conflicts of Interest}

We declare that we have no financial and personal relationships with other people or organizations that can inappropriately influence our work.

\section{Acknowledgments}

The authors are grateful for the National Natural Science Foundation of China (52075096) and Science Foundation of Nanjing Institute of Technology (YKJ201814).

\section{References}

[1] G. Hirn, "Sur les principaux phénomènes qui présentent les frottements médiats," Bulletin de la Société Industrielle de Mulhouse, vol. 26, pp. 188-277, 1854.
[2] P. Samanta, N. C. Murmu, and M. M. Khonsari, "The evolution of foil bearing technology," Tribology International, vol. 135, pp. 305-323, 2019.

[3] T. Raparelli, V. Viktorov, F. Colombo, and L. Lentini, "Aerostatic thrust bearings active compensation: critical review," Precision Engineering, vol. 44, pp. 1-12, 2016.

[4] K. Sim and J. Park, "Performance measurements of gas bearings with high damping structures of polymer and bump foil via electric motor driving tests and one degree-of-freedom shaker dynamic loading tests," Journal of Engineering for Gas Turbines and Power, vol. 139, no. 9, 2017.

[5] M. Moradi, F. Colombo, T. Raparelli, A. Trivella, and V. Viktorov, "Dynamic lumped model of externally pressurized rectangular air bearings," Precision Engineering, vol. 56, pp. 101-112, 2019.

[6] Y. LI and F. DUAN, "Interference torque of a three-floated gyroscope with gas-lubricated bearings subject to a sudden change of the specific force," Chinese Journal of Aeronautics, vol. 32, no. 3, pp. 737-747, 2019.

[7] T. Rybus, K. Seweryn, J. Oleś et al., “Application of a planar air-bearing microgravity simulator for demonstration of operations required for an orbital capture with a manipulator," Acta Astronautica, vol. 155, pp. 211-229, 2019.

[8] D. Ghodsiyeh, F. Colombo, T. Raparelli, A. Trivella, and V. Viktorov, "Diaphragm valve-controlled air thrust bearing," Tribology International, vol. 109, pp. 328-335, 2017.

[9] K. Feng, W. Liu, R. Yu, and Z. Zhang, "Analysis and experimental study on a novel gas foil bearing with nested compression springs," Tribology International, vol. 107, pp. 65-76, 2017.

[10] A. Kingsbury, "Experiments with an air-lubricated journal," Journal of the American Society for Naval Engineers, vol. 9, no. 2, pp. 267-292, 1897.

[11] S. J. Hughes, S. I. Hogg, and T. V. Jones, "Analysis of a gas lubricated hydrodynamic thrust bearing," vol. 118 , no. 3, pp. 449-456, 1996.

[12] M. Otsuka, "Self-acting air-lubricated bearing without oil lubrication," R\&D Review of Toyota CRDL, vol. 41, no. 1, pp. 24-35, 2005.

[13] M. Ochiai, H. Sasaki, Y. Sunami, and H. Hashimoto, "Experimental and theoretical verification of impact response on air thrust bearing with topological optimized groove," Tribology Online, vol. 10, no. 2, pp. 115-120, 2015.

[14] M. R. Pattnayak, R. K. Pandey, and J. K. Dutt, "Performance behaviours of a self-acting gas journal bearing with a new bore design," Tribology International, vol. 151, article 106418, 2020.

[15] M. Fesanghary and M. M. Khonsari, "On the optimum groove shapes for load-carrying capacity enhancement in parallel flat surface bearings: theory and experiment," Tribology International, vol. 67, pp. 254-262, 2013.

[16] R. H. M. Franssen, W. Potze, P. de Jong, R. H. B. Fey, and H. Nijmeijer, "Large amplitude dynamic behavior of thrust air bearings: modeling and experiments," Tribology International, vol. 109, pp. 460-466, 2017.

[17] N. LaTray and D. Kim, "Design of novel gas foil thrust bearings and test validation in a high-speed test rig," Journal of Tribology, vol. 142, no. 7, 2020.

[18] Z. Kozanecki, J. Łagodziński, E. Tkacz, and K. Miazga, "Performance of thrust airfoil bearing for oil-free turbomachinery," Journal of Vibration Engineering \& Technologies, vol. 6, no. 1, pp. 1-6, 2018. 
[19] T. Ise, M. Osaki, M. Matsubara, and S. Kawamura, "Vibration reduction of large unbalanced rotor supported by externally pressurized gas journal bearings with asymmetrically arranged gas supply holes (Verification of the effectiveness of a supply gas pressure control system)," Journal of Tribology, vol. 141, no. 3, 2019.

[20] C. Jia, H. Zhang, S. Guo, M. Qiu, W. Ma, and Z. Zhang, "Study on dynamic characteristics of gas films of spherical spiral groove hybrid gas bearings," Proceedings of the Institution of Mechanical Engineers, Part J: Journal of Engineering Tribology, vol. 233, no. 8, pp. 1169-1181, 2019.

[21] W. Xu and J. Yang, "Accuracy analysis of narrow groove theory for spiral grooved gas seals: a comparative study with numerical solution of Reynolds equation," Proceedings of the Institution of Mechanical Engineers, Part J: Journal of Engineering Tribology, vol. 233, no. 6, pp. 899-910, 2019.

[22] G. Stachowiak and A. W. Batchelor, Engineering tribology, Butterworth-Heinemann, 2013. 